ГАДЖИЕВ Камалудин Серажудинович - доктор исторических наук, профессор, главный научный сотрудник Национального исследовательского института мировой экономики и международных отношений РАН им. Е.М. Примакова (117997, Россия, г. Москва, Профсоюзная ул., 23; zuhrabvi@ yandex.ru)

\title{
О ДЕМОНИЗАЦИИ ПРОТИВНИКА ВО ВНЕШНЕПОЛИТИЧЕСКОЙ СТРАТЕГИИ США
}

\begin{abstract}
Аннотация. Вполне сознавая, что политическая стратегия представляет собой комплекс множества компонентов, автор исходит из установки, что при определенных условиях великие державы в своей внешнеполитической стратегии склонны использовать различные методы и средства, не всегда соответствующие нормам и правилам взаимовыгодного сотрудничества. К ним автор относит демонизацию руководством США своих противников, прежде всего Российской Федерации, рассматриваемой как главный враг. В последние годы использование Вашингтоном демонизации России, дополненное попытками ее дегуманизации и делигитимации, приобрело беспрецедентные масштабы. Для этого используются новейшие средства информационно-идеологической войны, такие как псевдособытия или фейковые доказательства - от скандально известных «пробирок Пауэлла» до обвинений в хакерском вмешательстве России в президентские выборы 2016 г. в США, имитации отравления отца и дочери Скрипалей в Солсбери и др.
\end{abstract}

Ключевые слова: США, Россия, политика, стратегия, враг, противник, государство, сверхдержава, демонизация, конфликт, война

$\mathrm{K}$ ак свидетельствует исторический опыт, человек, человеческие сообщества, особенно государство, империя, цивилизация, не могут обойтись без образа действительного или воображаемого врага, который им необходим для своего raison d'état. Его нельзя рассматривать как некое отклонение от нормы, некий атавизм, реликт, унаследованный человеком от своего животного предка. Чужой, враг, «не мы» представляют собой естественные проявления человеческой природы. Отношения между людьми основаны не только на бескорыстии, симпатии, уважении, доверии, любви друг к другу, но также на недоверии, антипатии, конкуренции, противоречиях, конфликтности, нередко доходящих до враждебности.

Как не без оснований отмечал немецкий политический философ К. Шмитт, «то, что народы группируются по противоположности “друг-враг”, что эта противоположность и сегодня действительна и дана как реальная возможность каждому политически существующему народу, - это разумным образом отрицать невозможно». В отношениях между народами, государствами понятие «враг» пронизано политическим началом и теснейшим образом связано с понятиями «Конфликт», «борьба», «война» противоборствующих сил, организованных политически.

Именно на этой основе, как говорится, уже с начала времен появились антитезы: «мы-они», «свои-чужие», «племя - враг племени». Согласно закону противоречия, формулы «мы-они», «свои-чужие», «друг-враг» имеют обратную силу, поскольку, скажем, в дихотомии «мы-они», «мы» и «они» меняются местами. Иначе говоря, имидж по определению предполагает контримидж. Образ реального или воображаемого врага играет как бы двойственную роль. С одной стороны, он служит инструментом консолидации, единства, сплоченности коллектива, сообщества, народа вокруг общей воли, идеала, общего интереса, цели, с другой - для размежевания с внешними контрагентами. В обоих случаях если нет реального противника/врага, то его необходимо придумать, сконструировать. Его исчезновение с политической арены может создать у со- 
ответствующего народа, государства ощущение некоей пустоты, потери чего-то очень важного.

При таком понимании может быть, что распад СССР, который рассматривался Западом, прежде всего США, в качестве главного врага, внес определенные неурядицы в систему их миропонимания, трактовки реалий современного мира. В период двухполюсного миропорядка враг в лице СССР и ассоциировавшиеся с ним антисоветизм и антикоммунизм в США использовались в качестве инструментов мобилизации, объединения, консолидации, с одной стороны, американского народа вокруг власти внутри страны и, с другой стороны, всего западного мира вокруг Вашингтона против общего врага. В качестве системообразующих ценностей и средств они играли такую же роль, как идеи американской исключительности, американского века, предопределения судьбы (manifest destiny) и др.

Иными словами, государство нуждается в «коварном враге» для целей внутренней и внешней мобилизации. С учетом этих рассуждений можно согласиться с известным американским историком и политологом С. Хофманом, который, исследовав менталитет американцев того периода, пришел к выводу, что в условиях двухполюсного миропорядка они воспринимали противоречия между США и СССР в «противоборствующем, почти шизофреническом свете». Господствовала тенденция интерпретировать любые действия противной стороны как «часть хорошо продуманного и широкого плана», направленного против США. При этом, утверждал Хоффман, приписывая противнику всякие козни, «мы, американцы, в действительности не ставили под сомнение наше моральное и материальное превосходство» [Hoffman 1980: 8].

Феномен врага с окончанием «холодной войны» и биполярного миропорядка отнюдь не исчез и не мог исчезнуть, поскольку на месте исчезнувшего возникает или конструируется новый враг, принимающий иные формы и ипостаси, наделяемый иными атрибутами и характеристиками. Если в период двухполюсного миропорядка вопрос о взаимных врагах и друзьях, чужих и своих, противниках и союзниках решался без особых трудностей, то после распада СССР и двухполюсного миропорядка и формирования вслед за ним либерального/однополярного эта задача существенно осложнилась. Не стал этот вопрос легко решаемым в условиях распада либерального/однополярного и формирования нового полицентрического миропорядка. Тем не менее в силу комплекса факторов в Стратегии национальной безопасности США, обнародованной Д. Трампом 18 декабря 2017 г., Россия вместе с Китаем названы «ревизионистскими державами», т.е. врагами, якобы представляющими главную угрозу их национальной безопасности. При этом, руководствуясь создавшимися в данный конкретный период условиями и во многом конъюнктурными соображениями, она рассматривает Россию как главное препятствие на пути реализации декларированной Д. Трампом цели «сделать Америку вновь великой».

Россия действительно не признает установленную Вашингтоном табель о рангах. Поэтому, естественно, в глазах руководителей ряда ведущих стран Запада, не говоря уже о неофитах из Восточной Европы и стран Балтии, Россия предстает как величина отрицательная. Именно в ней, во всяком случае на данный момент, усматривают главную, можно утверждать, экзистенциальную угрозу либеральному/однополярному миропорядку, политической демократии, западному/американскому образу жизни, американской гегемонии в мире. Поэтому ставится цель лишить Россию опоры, изолировать ее, всеми возможными и невозможными средствами вывести на периферию глобальной политики. По аналогии с известной формулой: «Карфаген дол- 
жен быть разрушен» Запад пытается изолировать, загнать Россию в геополитическое гетто или же расчленить, чтобы «пикнуть не смела» против воли гегемона. Такая позиция призвана показать как самим себе, так и остальному миру, особенно народам, государствам, готовым сотрудничать с Россией, кто именно в мире хозяин.

Предпринимаются попытки дегуманизации, демонизации и, соответственно, делигитимации государства-противника, его представления в глазах так называемого мирового сообщества, под которым подразумевается Запад с населением всего примерно в 1/7 часть населения земного шара. На политическую и идеологическую потребу дня для поставленных целей используются искусственно конструируемые мифы о реальных или воображаемых угрозах национальной безопасности. Для их навязывания тому или иному государству и даже мировому сообществу оказываются достаточными псевдособытия или фейковые доказательства вроде скандально известных «пробирок Пауэлла», обвинений в хакерском вмешательстве России в президентские выборы 2016 г. в США, имитации отравления отца и дочери Скрипалей в Солсбери в марте 2018 г. или грубом постановочном видеопоказе якобы химической атаки властей Дамаска 7 апреля 2018 г. в городе Думе и др.

Осуществляя такую политику, руководство и значительная часть политического и медийного истеблишмента США одержимы представлением о своем мнимом всемогуществе, дополнительный стимул которому придает отсутствие должного сопротивления со стороны незападной части мирового сообщества. При этом имеет место всевозрастающий дисбаланс между финансовыми и военными возможностями, с одной стороны, и безответственностью и фанаберией - с другой. Треть века назад, лишившись противовеса и внешнего контроля, Америка утратила самоконтроль и необходимые в таких ситуациях внутренние самоограничения. А дальше - «любая власть развращает, а абсолютная власть развращает абсолютно». Здесь ключевое значение имеет феномен надменности силы, силы, которая не встречает сопротивления, отпора. Она усиливается безнаказанностью. Тем более, что положение вещей в мире сложилось таким образом, что за широкомасштабные военные преступления виновные не несут наказание. Или, перефразируя великого писателя, преступление остается без наказания. Поверженную Германию во Второй мировой войне можно было судить на международном Нюрнбергском процессе. США за ничем не оправданную кровавую агрессию против Ирака и других стран, которая обернулась хаосом, фактическим распадом суверенных государств, нельзя предать суду народов, потому что сила на их стороне. Установившееся право сильного позволяет Вашингтону игнорировать международное право и действовать по закону права сильного.

Одно из весьма интересных проявлений новизны этих процессов состоит в том, что в переходный период от одного типа миропорядка к другому ключевые акторы мировой политики, особенно те, которые, достигнув пика своего могущества, вступили на путь, ведущий к ослаблению, как бы теряют способность выбрать «друзей» и «врагов». Как известно, в 70-х гг. прошлого века тогдашний государственный секретарь США Г. Киссинджер выдвинул формулу стратегического треугольника, с помощью которой Вашингтон ставил своей целью сдерживание СССР путем нормализации отношений с Китаем при одновременном ухудшении отношений между Москвой и Пекином. Частью этой формулы стала идея Киссинджера «никогда не допускать союза России и Китая». Нынешние руководители западных стран, прежде всего США, нарушают этот принцип. Во многом благодаря политике Вашингтона сближение эти двух гигантов стало свершившимся фактом. Как отмечал Зб. Бжезинский, 
«для Соединенных Штатов не может быть ничего опаснее тесного союза этих двух держав»1.

При этом нельзя не обратить внимание на тот факт, что в силу комплекса причин преимущественное внимание коллективного Запада в настоящее время сконцентрировано на России, а не на Китае, объективно представляющем для них значительно большую опасность. Дело в том, что Россия оказалась на острие сопротивления Западу в целом и США в особенности. Поэтому Вашингтон пытается найти решение проблемы путем «добивания» России, ее выбивания из игры как слабейшего, по их мнению, звена в тандеме РоссияКитай. Средством достижения данной цели выбрано стремление сначала изолировать и нейтрализовать первую, чтобы, в конечном счете, со всей мощью обрушиться на Поднебесную.

В этом контексте лозунг: «Вернуть Америке величие» нужно принимать весьма серьезно. Это основа долговременной внешнеполитической стратегии США. Причем программы, формы, пути, средства его реализации могут приобретать все возрастающий радикализм по мере укрепления мощи и притязаний других акторов мировой политики, не согласных с либеральным/однополярным миропорядком.

В действительности никто так не разрушает устои либерального/однополярного миропорядка, как сами его главные адепты, растаптывающие основополагающие нормы международного права. Парадоксальным образом одним из таких адептов является главный бенефициарий этого миропорядка, который своими действиями вносит в его разрушение больший вклад, чем какой-либо из его последовательных противников. Речь идет, прежде всего, о подрыве принципа верховенства во внешнеполитической сфере международного права.

С рассматриваемой точки зрения доверие/недоверие играет ключевую роль во взаимоотношениях между государствами. Речь идет, прежде всего, о том, каков уровень преобладания в их сознании взаимного доверия или недоверия, как они видят и воспринимают друг друга. От этого во многом зависит уровень договороспособности государства и легитимность заключаемых между государствами договоров. Взаимное доверие можно оценивать как своего рода предварительное условие, индикатор нормальных отношений между ними. При низком уровне или же отсутствии доверия любой договор рано или поздно может превратиться в бесполезный клочок бумаги. Более того, недоверие, перерождающееся в подозрительность и, в конечном счете, во враждебность, не сулит ничего хорошего в плане достижения согласия между противоборствующими сторонами по ключевым вопросам мировой политики.

С феноменом врага, недоверием контрагентов друг к другу теснейшим образом связан страх. Если есть враг, то по самому своему определению предполагается, что от него исходит угроза интересам соответствующего сообщества, может быть, и самому его существованию. Здесь наряду с реальными немаловажную роль в современном мире играют воображаемые, иллюзорные, искусственно муссируемые угрозы. По справедливому замечанию Н.А. Бердяева, «самые страшные люди - это люди, одержимые страхом». Страх, который «правит миром», разрушителен по своей природе. Он «скрывает истину и связан с ложью и жестокостью» [Бердяев 1993]. Касаясь положения вещей в этой сфере в США, ныне покойный Зб. Бжезинский писал: «"Война с террором” породила в Америке атмосферу страха. После ужасных событий 11 сентября это словосочетание, превратившись по милости администрации Буша в общенациональ-

\footnotetext{
${ }^{1}$ Бжезинский Зб. Кризис мировой власти и тройственный союз США, Китая и России. - Россия в глобальной политике. 9 января 2017. Доступ: http://globalaffairs.ru/global-processes/Krizis-mirovoi-vlastii-troistvennyi-soyuz-SShA-Kitaya-i-Rossii-18528 (проверено 10.06.2018).
} 
ное “заклинание”, оказывает губительное воздействие на американскую демократию, психику наших сограждан и положение США в мире», в силу чего все возрастающее число американцев «поддается паранойе» [Бжезинский].

Как известно, подобное состояние порождает такие феномены, как охота на ведьм, инквизиция, крестовые походы, религиозные войны, геноцид, терроризм и т.д. Такое состояние общественного сознания США, которое известный американский историк Р. Хофстедтер, характеризуя период маккартизма 50-х гг. прошлого века в США, назвал «параноидным стилем», порождает заговорщический комплекс, доводящий недоверие, подозрительность и ненависть до уровня мировоззренческого кредо. Такой тип сознания поощряет односторонность, редукционизм, склонность загонять все и вся в прокрустово ложе одной единственной особенно полюбившейся идеи. Речь идет в некотором роде о тенденции к большевизации менталитета определенной части западного политического, интеллектуального и медийного истеблишмента, который подсознательно чувствует, что привычный порядок, основанный на ценностях, установках, принципах либерализма, не во всем стыкуется с новыми мировыми реалиями и начинает давать трещину. Эта тенденция проявляется, в частности, в радикальной трактовке либерализма как единственной и окончательной истины в последней инстанции. Естественно, преобладает убеждение в том, что Запад, «оседлавший» эту истину, одержал полную и окончательную победу во всемирном масштабе. Для всего человечества иной альтернативы, кроме как либерализм, не существует и не может существовать. В этом контексте остальной мир рассматривается как своего рода окрестности Америки. По сути дела, всему современному миру предлагается нечто вроде формулы автомобильного магната Генри Форда: «Среди наших черных автомобилей вы можете выбрать автомобиль любого цвета, какого захотите». В данном случае, конечно, странно было бы захотеть выбрать автомобиль белого цвета. В этом контексте можно адекватно понять заявление президента Дж. Буша-младшего, который после террористической атаки исламистов 11 сентября 2001 г. заявил всему миру: «Вы либо с нами, либо против нас», что, по сути дела, является парафразой известного выражения: «Кто не с нами, тот против нас».

Во все периоды истории империя наращивала свою мощь, прежде всего за счет территориальных завоеваний. Западная капиталистическая цивилизация с самого начала была ориентирована на экспансию, которую можно назвать альфой и омегой самоопределения, экзистенциальной основой империи. Не случайно составной частью евроцентристского, евро-атлантического мира стали великие колониальные империи. И в наши дни жизненным стимулом, генератором витальной энергии США остается внешняя экспансия. США, превратившиеся в своего рода локомотив экономического и технологического прогресса, будучи по своей природе империей, по определению не может существовать без экспансии - территориальной, экономической, культурной, медийно-информационно-идеологической, военной и т.д.

Очевидными проявлениями этой экспансии стали внешнеполитическая стратегия, направленная на практическую реализацию скандально известных идей об окончательной победе во всемирном масштабе ценностей западного либерализма, стратегия, которая вылилась в политику экспорта так называемой демократической революции, а также тех агрессивных войн, которые Вашингтон развязал на Ближнем Востоке и Северной Африке. В этом же русле нельзя не отметить стремление распространить юрисдикцию англосаксонского права в его американской трактовке на весь остальной мир. Эта позиция проявляется, в частности, в стремлении застолбить за Вашингтоном полномочия формулировать нормы и правила поведения на международной арене всему остальному 
миру. Это без всякой толики сомнения в своей правоте декларировал, будучи президентом США, Барак Хусейн Обама. «Когда более 95\% наших потенциальных клиентов живут за пределами наших границ, - утверждал он, - мы не можем позволить странам вроде Китая писать правила глобальной экономики. Мы должны писать эти правила, открывая новые рынки для американской продукции и устанавливая высокие стандарты для защиты работников и сохранения окружающей среды» ${ }^{1}$.

Альфой и омегой этой стратегии является жесткая установка: любой ценой сохранить финансовую систему современного мира, основанную на долларе и в меньшей степени на евро, или же, проще говоря, статус доллара как основополагающей мировой валюты. Суть вопроса состоит в том, что доллар в качестве мировой валюты вкупе с военной мощью выступают в качестве двух краеугольных камней империи. Они дополняют друг друга и, возможно, питают друг друга, лишены жизнеспособности друг без друга. Доллар всесилен, потому что он опирается на военно-политическую и экономическую мощь, а эта последняя, в свою очередь, зиждется на силе и влиянии доллара. Угроза доминирующей роли доллара - это экзистенциальная угроза национальной безопасности США, во всяком случае их имперскому статусу. Ведь при создавшихся ныне геополитических условиях никто не способен прогнозировать реальные перспективы США при гипотетической потере долларом способности «оседлать» всю мировую финансовую систему. Поэтому, естественно, Вашингтон, как представляется, готов предпринять все возможные и невозможные меры для его защиты

Здесь проблема заключается в том, что конфронтационная политика и США, и России друг против друга ориентирована на самоутверждение. Если Вашингтон пытается сохранить тающие на глазах всемогущество и претензии на мировую гегемонию, то Россия стремится восстановить утерянный после распада СССР статус великой мировой державы. Обе противоборствующие стороны к настоящему времени не готовы отказаться от своих позиций. Комплекс триумфализма мешает Западу, прежде всего США, отказаться от присвоенного самому себе статуса первого среди равных. Они чуть ли не свято верят в реальность, более того - в неизбежность, необходимость и незыблемость своей гегемонии.

В этом контексте Америка во все возрастающей степени из одного из ключевых акторов мировой политики, призванных разрешать жизненно важные для всего человечества проблемы, превращается в главного зачинщика международной напряженности, межнациональных, региональных и глобального масштаба конфликтов. Такое положение сохранится пока Америка не подвергнет значимой переоценке свои основополагающие ценности: исключительность, предназначение самим Провидением к особой - руководящей - роли в мире, роли «сияющего града на холме» в пример всем другим народам мира, «предопределение судьбы» (manifest destiny) и т.д., все останется, как есть. Но без них Америка не будет той Америкой, какой ее видят и оценивают сами американцы. Поэтому она не захочет, да просто и не способна подвергнуть сомнению свой выбор.

При этом геополитическое положение в современном мире со всей очевидностью демонстрирует все более четко проявляющуюся тенденцию к беспрецедентному сжатию, подобно шагреневой коже, пространства гегемонии США и, соответственно, их конструктивного взаимодействия с остальным миром. К тому же Запад в целом и США в не последнюю очередь неуклонно

1 Обама: правила мировой торговли будут писать США, а не другие страны. - РИА «Новости». 05.10.2015. Доступ: https://ria.ru/economy/20151005/1297170265.html (проверено 10.06.2018). 
теряют в глазах остального мира право на претензию морального превосходства, на ценностное, культурное и идеолого-информационное доминирование.

Многие из среды американской политической и интеллектуальной элиты прекрасно сознают, что времена радикально изменились, соответственно, иными становятся геополитический статус, относительная военно-политическая мощь, возможности США диктовать свою волю остальному человечеству и т.д. Здесь считаю целесообразным как бы вывести за скобки общеизвестные рассуждения как противников либерального миропорядка, таких как американский общественный деятель и аналитик П.Дж. Бюкенен, французский исследователь Э. Тодд и др., которые говорят чуть ли не о «смерти Запада» и «конце американской империи», так и признанных аллилуйщиков триумфа либерализма и триумфализма Запада в лице, например, Зб. Бжезинского, Ф. Фукуямы и др., которые вынуждены признать конец гегемонии США. Чтобы показать сдвиги в позициях все возрастающего числа представителей западного либерализма, считаю уместным привести доводы американского аналитика Ч. Краутхаммера и английского политолога и экономиста Э. Льюса.

Ч. Краутхаммер, в течение многих лет связанный с престижным журналом либеральной ориентации The Republic, сравнив распад CCCP и исчезновение коммунизма с «зарей» и «расцветом» современного мира, писал: «Эта заря ознаменовала окончательную победу либерально-демократической идеи. Этот рассвет сулил наступление эпохи доминирования Запада во главе с превосходящей всех остальных Америкой - последней из оставшихся в мире сверхдержав. И именно так и было на протяжении десяти лет». Однако, с глубокой горечью констатирует Краутхаммер, теперь эпоха «бурного и пьянящего исторического торжества либеральной демократии завершилась» ${ }^{1}$.

В свою очередь, Э. Льюс, характеризуя настроения западной интеллигенции 1989 г. и нынешнее положение вещей в этой сфере, писал: «Выросшие среди ядерных призраков холодной войны, мы не могли устоять перед соблазном хоть одним глазком увидеть свидетельства ее физической кончины». В 1989 г., будучи еще студентом философии, политики и экономики в Оксфордском университете, он в радостной эйфории вместе с тысячами людей «молодых и пожилых, немцев и иностранцев... зубилами и кирками» долбили Берлинскую стену ${ }^{2}$. Оценивая нынешнее положение, Льюс с горечью констатирует: «Мы были больны оптимизмом... Для человека, чья жизнь совпала с расцветом демократии, распространением рыночной экономики и первыми признаками того, что мир, наконец, присоединился к Всеобей декларации прав человека, мучительна уже сама постановка этого вопроса [о победе Запада]. Разве эти споры не разрешились много лет назад? Разве весь мир не стремится жить по западному образцу? Уверенности в этом уже нет. С нашей стороны было большой самонадеянностью полагать, что остальной мир пассивно усвоит предложенную нами модель» 3 . Проблему современного Запада Льюс видит в его «болезни прогрессом». Здесь представляется уместным, перефразировав этот диагноз Льюса, констатировать: Запад болен триумфализмом, и избавиться от него может оказаться весьма трудным делом. Создается впечатление, что коллективный Запад, прежде всего США, соблазненный якобы одержанной победой над всем остальным человечеством, не хочет, не может и не собирается признавать новые реалии.

\footnotetext{
${ }^{1}$ Krauthammer Ch. After a mere 25 years, the triumph of the West is over. - The Washington Post. 2016. December 1. 2016

2 Luce E. The siege of western liberalism. - Financial Times. 2017. May 5.

3 Ibid.
} 
Суть вопроса заключается в том, что для обеих сторон - как для США, так и для России - угроза носит экзистенциальный характер, в силу чего ни одна из них не склонна отступать, не желает, а в создавшихся условиях - и не может «потерять лицо». Америке просто не позволено потерять в глазах союзников, да и всего остального мира, самопровозглашенный статус защитницы либеральных ценностей прав человека, демократии, либерального/однополярного миропорядка и единственного «законного» творца обязательных для всего остального мира норм и правил поведения на международной арене. Со своей стороны, «ревизионистские державы» вкупе с остальным миром (может быть, пассивно наблюдающим за происходящими в мире процессами) также полны решимости отстаивать свои жизненно важные интересы.

Попросту говоря, любая сторона, уступив другой, понесет тяжелейшие геополитические потери. Поэтому отступать некуда ни Вашингтону, ни Москве. Развитие событий в этом направлении может привести к ситуации, в которой результатом отсутствия должного ответа той или иной стороны на ту или иную более или менее серьезную угрозу национальной безопасности, как показывает исторический опыт, могут стать еще более серьезная угроза и одновременно национальное унижение и позор. Таков реальный принцип взаимоотношений между великими державами.

В период двухполюсной конфронтации между Востоком и Западом действовал определенный комплекс признанных и в целом соблюдаемых обеими сторонами норм, правил политического поведения. Обе стороны знали, кто друг, и кто враг, кто союзник и кто противник, где именно пролегают те красные линии невозврата, или рубиконы, которые рассматривались обеими сторонами как точки невозврата, и поэтому ни при каких обстоятельствах их нельзя пересечь. Через всю «холодную войну» периода двухполюсного миропорядка красной нитью проходило понимание необходимости соблюдения этого правила. При всех возможных оговорках две противоборствующие стороны были склонны к взаимным компромиссам по ключевым вопросам международной и национальной безопасности. Было ясное понимание ядерной войны как акта безумия, ведущего человечество к самоуничтожению. Возможно, не случайным представляется тот факт, что выражение «гарантированное взаимное уничтожение», которое на английский язык переводится как mutual assured destruction, в аббревиатуре выражается как MAD. Как известно, английское слово mad переводится как «безумный».

Иное положение сложилось в наши дни. Наблюдается тенденция к девальвации такого понимания ядерной войны. Более того, для ее оправдания говорят о возможности локальной ядерной войны, тактического применения ядерного оружия против противника. Красные линии, рубиконы оказываются как бы размытыми, потеряли былую значимость, стали, условно говоря, пересекаемыми, во всяком случае в сознании многих государственных деятелей, военачальников, особенно пишущей братии. И это еще не все. С величайшим сожалением приходится констатировать, что ядерное оружие отнюдь не отменило возможность невозможного, поскольку, как показывает исторический опыт, человек и человеческие сообщества часто действовали вопреки очевидному.

Эта тенденция органически сочетается с подобными же процессами в других сферах общественно-политической жизни, прежде всего коллективного Запада. Речь идет, к примеру, о деградация олимпийского движения, превратившегося в арену политической и идеологической войны «победившего» Запада или, вернее, англосаксонского мира против остального человечества. Все более очевидными становятся попытки превращения (если уже не окончательное превра- 
щение) Олимпиады из инструмента объединения народов в арену их взаимного разъединения, вражды, борьбы.

Имеет место фактическая деградация некогда считавшихся престижными средств массовой информации, главной проблемой которых стала фейкизация, суть которой состоит в распространении выдуманных, сфабрикованных на потребу дня новостей. Нарушается всякого рода дипломатический этикет, морально-этические нормы; высшие должностные лица так называемых цивилизованных демократических государств в дискуссиях в критике оппонентов, в т.ч. и с трибуны Совета Безопасности ООН, не брезгуют уличной лексикой.

По мере деградации международного права, традиционных норм и правил поведения между суверенными государствами разрабатываются весьма изощренные формы и методы поиска и выбора врагов, их последующей дегуманизации и демонизации. В политический лексикон вошли противоестественные понятия «государства-изгои», «империя зла» и др.

Оценивая эти тенденции и сдвиги, мы склонны, как можно убедиться из только что приведенных рассуждений, рассматривать их как деградацию традиционных некогда престижных, гордящихся своим статусом средств массовой информации, международного права, морально-этических норм и дипломатического этикета в отношениях между государствами и т.д. Возможно, это так.

Однако, как представляется, речь, возможно, идет о другом. Любые законы, нормы, правила, статусы, олимпийские и иные гуманистической ориентации хартии, какими бы так называемыми правовыми, гуманными или иными они ни были, составляются применительно к конкретным ситуациям, характерным для конкретного положения вещей конкретного исторического периода. Причем они составляются победителями в интересах самих победителей. Более того, победители в зависимости от положения дел в мире присваивают себе право по-своему интерпретировать их и по сути дела нарушать их основной смысл. Победителем был евроцентристский (или западоцентристский) мир, и либеральный миропорядок был создан именно ведущими государствами этого мира. Той эпохе пришел конец, или же она находится на пути к завершению. Наступила или наступает другая, качественно новая эпоха. Мир стал или становится другим и, соответственно, порождает новые вызовы и новые угрозы, требующие новых ответов. Соответственно, по самой логике вещей нормы и правила игры на геополитической арене подлежат корректировке, во всяком случае с учетом интересов новых акторов - несущих опор нового полицентрического миропорядка.

Как писал К. фон Клаузевиц, «война есть не только политический акт, но и подлинное орудие политики, продолжение политических отношений, проведение их другими средствами» [Клаузевиц 1937: 54]. Признавая правоту немецкого генерала и теоретика войны, в то же время считаем необходимым внести в эту максиму определенные коррективы. Как правило, в условиях войны конфронтационность, упор на силовые методы вовлеченных в нее сторон приобретает настолько интенсивные и крайние формы, что сама политика в традиционном смысле как бы отодвигается на задний план или даже элиминируется. По аналогии с известным выражением: «Когда говорят пушки - музы молчат», можно утверждать, что с началом войны политики должны молчать, или, во всяком случае, они отодвигаются на вторые роли. Здесь отчетливо проводится грань между «своими» и «чужими», «друзьями» и «врагами» как бы в предельно очищенном от морально-этических, нравственных, политических и иных критериев виде. 
И еще. Г. Киссинджер не без оснований на то говорил: «...демонизация Путина - это не политика; это алиби для ее отсутствия»1. Верность данного суждения состоит в том, что демонизация, вытекающая из радикализма и черно-белой трактовки мировых реалий и отношений с противником, тем более сильным противником, способным адекватно ответить на любой вызов противной стороны, никоим образом не служит решению сколько-нибудь серьезных проблем, касающихся национальной и международной безопасности. Иначе говоря, демонизация, будучи своеобразным актом войны, также как бы ведет к отрицанию, делигитимации политики в собственном смысле слова.

\title{
Список литературы
}

Бердяев Н. 1993. О назначении человека. Экзистенциальная диалектика божественного и человеческого. М.: Республика. 383 с.

Бжезинский 3б. Стратегический взгляд: Америка и глобальный кризис. Доступ: http://litresp.ru/chitat/ru/\%D0\%91/bzhezinskij-zbignev/strategicheskijvzglyad-amerika-i-globaljnij-krizis.

Клаузевиц К. 1937. О войне. В 2 т. Т. І. Природа войны. О теории войны. О стратегии вообще. Бой. Вооруженные силы. М.: Воениздат.

Hoffman S. 1980. Primacy of the World Order. N.Y.: McGraw-Hill Inc. 331p.

GADZHIEV Kamaludin Serazhudinovich, Dr.Sci. (Hist.), Professor, Chief Researcher, Primakov National Research Institute of World Economy and International Relations (23 Profsoyuznaya St, Moscow, Russia, 117997; zuhrabvi@ yandex.ru)

\section{ON THE DEMONIZATION OF THE ENEMY IN FOREIGN POLICY STRATEGY OF THE US}

\begin{abstract}
Being fully aware that the political strategy is a complex of many components, the author proceeds from the view that under certain conditions the great powers are inclined to use in their foreign policy strategy various methods and means that do not always correspond to the norms and rules of mutually beneficial cooperation. The author refers to them the demonization by the leadership of the US the opponents, first off, the Russian Federation, considered to be the main enemy. The focus is on substantiating the thesis that in recent years Washington's use of Russia's demonization, supplemented by attempts to dehumanize and delegitimize it, has taken on an unprecedented scale. For this, the latest information and ideological warfare is used, such as pseudo-events or fake proofs from scandalously known Powell test tubes to accusations in Russia's hacker intervention in the US presidential election in 2016, imitation of poisoning of the father and the daughter Scripals in Salisbury, etc.
\end{abstract}

Keywords: USA, Russia, politics, strategy, enemy, state, superpower, demonization, conflict, war

1 Как демоны США демонизируют Путина. Доступ: http://maxpark.com/community/5134/ content/3106099 (проверено 10.06.2018) 